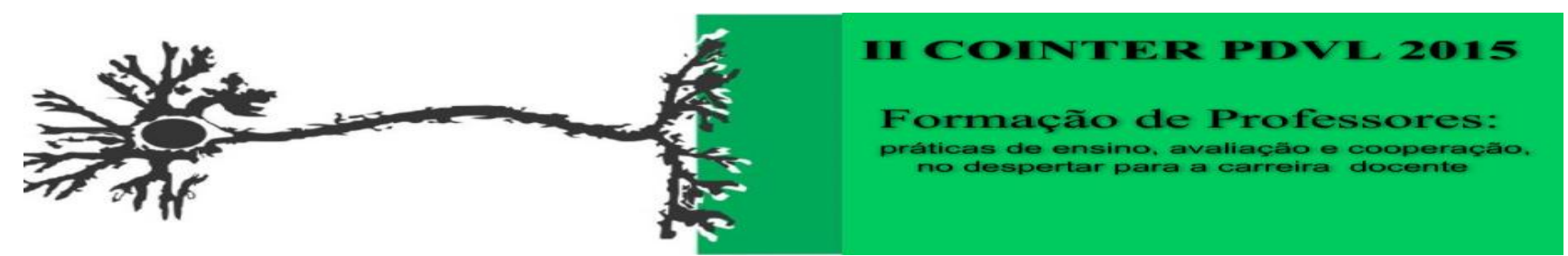

\title{
ESTÁGIO SUPERVISIONADO EM GEOGRAFIA: RELATO DE EXPERIÊNCIA VIVENCIADA NO ENSINO FUNDAMENTAL
}

\author{
Apresentação: Pôster \\ Elisângela Correia da Cunha ${ }^{1}$, Danuzia Lira de Sá Cabral ${ }^{2}$, Levi Rodrigues de Miranda ${ }^{3}$
}

\section{Introdução}

O presente trabalho foi desenvolvido a partir da iniciação da prática de ensino na Escola Estadual Professora Josefa Sampaio de Ensino Fundamental e Médio, localizada na avenida Café Filho Bairro Santos Reis Natal/RN e realizado como prática obrigatória da disciplina Estágio Supervisionado em Prática do Ensino III, no curso de Licenciatura em Geografia, do Instituto Federal de Educação, Ciência e tecnologia do Rio Grande do Norte. A melhor maneira para descobrir como funciona as etapas da aprendizagem é adquirir experiência em sala, mas é necessário também ter preparação e procurar se aperfeiçoar em sua prática diária. O objetivo desse trabalho é apresentar as informações e o desenvolvimento que foram adquiridos no decorrer do Estágio Supervisionado em Geografia III, do $8^{\circ}$ ano realizado na Escola Estadual Professora Josefa Sampaio de Ensino Fundamental e Médio.

Como procedimento metodológico, iniciamos com a revisão bibliográfica por meio de consultas a livros e periódicos disponíveis em meios eletrônicos ou em acervos públicos. Além disso, foi realizado uma aula de campo para o Museu de Minérios no IFRN com o intuito de conhecer os recursos minerais existentes no Nordeste e no Brasil.

\section{Fundamentação teórica}

O estágio supervisionado em geografia é de fundamental importância para se colocar na prática os conhecimentos adquiridos, e consequentemente experiências que subsidiará para a futura profissão docente. Sendo "o estágio um campo de conhecimento e eixo curricular central nos cursos de formação de professores, possibilitando que seja trabalhado aspecto indispensável às construções

\footnotetext{
${ }^{1}$ Licenciatura em Geografia, Instituto Federal de Educação, Ciência e Tecnologia do Rio Grande do Norte, eliscunha2@yahoo.com.br

${ }^{2}$ Licenciatura em Geografia, Instituto Federal de Educação, Ciência e Tecnologia do Rio Grande do Norte, Danuzia.ifrn@gmail.com

${ }^{3}$ Mestre em Arquitetura, Professor do Instituto Federal de Educação, Ciência e Tecnologia do Rio Grande do Norte, levi.miranda@ifrn.edu.br
} 
da identidade, dos saberes e das posturas específicas ao exercício profissional docente" (Pimenta, 2004, p. 61). Nesta perspectiva a identidade de qualquer profissional é construída ao longo de sua trajetória, da convivência em sala de aula, logo é necessário que o docente procure ensinar o aluno, instigando sua imaginação, criticidade, memória e aptidão, desenvolver a personalidade, seu raciocínio lógico, ou seja, para que os mesmos possam se adaptar à realidade tornando-se um cidadão crítico e participativo.

É preciso que o professor trabalhe conteúdos fazendo uma conexão entre as escalas local e global, utilizando-se conjuntamente do cotidiano para aprender os saberes científicos tornando assim a geografia significativa para os alunos.

\section{Caracterização da escola}

A escola estadual Josefa Sampaio está localizada à rua Presidente Café Filho, no 18 , no bairro de Santos Reis e atende alunos da comunidade e de outros bairros, como por exemplo, da Zona Norte e Oeste. Fundada em 1995, a unidade de ensino nunca havia passado por uma reforma e parte de suas salas de aulas funcionava em um prédio anexo fora da escola, e de forma bastante precária. Além disso, os ambientes eram muito pequenos e não havia espaço para os professores. Em março de 2013, a escola foi reinaugurada pela então governadora do estado Rosalba Ciarlini que garantiu novas salas de aula no primeiro piso, novos laboratórios de informática e ciências, biblioteca, sala de recursos para alunos com deficiência, acessibilidade em todo prédio, pátio coberto, cozinhas, nova recepção, salas para direção, coordenação, secretaria, professores e arquivo, novos banheiros para funcionários e alunos, além de ter todos os seus espaços coletivos ampliados (Ver figura 1).

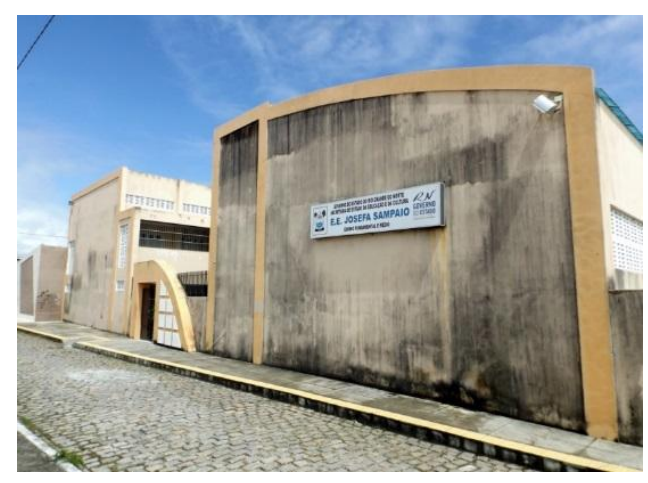

Fonte: GOMES 2014 


\section{Metodologia}

Como procedimento metodológico, iniciamos com a revisão bibliográfica por meio de consultas a livros e periódicos disponíveis em meios eletrônicos ou em acervos públicos. Além disso, foi realizado uma aula de campo para o Museu de Minérios no IFRN com o intuito de conhecer os recursos minerais existentes no Nordeste e no Brasil.

\section{Resultados e Discussões}

No primeiro instante fui muito bem recebida, pois como o primeiro e segundo estágio foram feitos na mesma escola já havia um certo conhecimento no que diz respeito a gestão. A vicediretora conversou comigo sobre os horários das aulas e sobre as mudanças que poderiam acontecer, pois os horários das aulas são feitos por semestre. De fato, as mudanças aconteceram, mas devido à preocupação da professora colaboradora e do diretor em não prejudicar meu estágio, o horário se adequou aos meus horários do IFRN, já que meu curso é no turno da noite.

Minhas aulas aconteciam sempre nas terças-feiras das 15:30 às 17:00 e nas sextas-feiras das 13:15 às 14:40 com duração de 45 minutos cada aula com intervalo de 15 minutos, onde como estagiária tive a oportunidade de prosseguir com mais uma experiência na instituição onde havia feito o estágio supervisionado I e II.

Com uma faixa etária entre 13 a 17 anos, essa turma é meio inquieta e ao registrar as atividades em seus cadernos muitas vezes reclamavam, pois eles não gostam de escrever, porém, algumas vezes são participativos durante a apresentação dos conteúdos e das atividades. Esta turma possui em torno de 15 alunos, e devido ao tamanho da sala se torna quase inviável o trânsito na mesma, pode ser que isto influencie no processo ensino-aprendizagem, pois segundo a professora colaboradora a turma apresenta dificuldade de aprendizagem e estava atrasada em relação ao conteúdo. Sendo assim, entendi o que a professora colaboradora me falou, logo quando fui me apresentar a turma pela primeira vez, que era preciso ter paciência com eles e ajudá-los para que eles se sentissem motivados.

$\mathrm{Na}$ sala do $8^{\circ}$ ano vespertino também está matriculada uma aluna chamada Jéssica que possui deficiência auditiva e que é acompanhada pela professora Mary (tradutora e intérprete de Libras). 
As aulas ministradas pela professora colaboradora eram baseadas no método tradicional com atividades em grupos, uso do livro didático, do quadro, pincel e outros materiais, vez em quando ela procurava tornar as aulas um pouco descontraídas, pois os alunos do $8^{\circ}$ período do turno vespertino são um pouco dispersos sendo preciso revisar sempre o tema para que os mesmos viessem assimilar o conteúdo. Nessa turma foi possível formar vários subgrupos de alunos: os atenciosos com facilidade para aprender e os desinteressados com dificuldade para aprender. Os conteúdos ministrados foram o mundo bipolar e multipolar.

Também apliquei uma atividade lúdica referente aos Blocos Econômicos como mostra a (Figura 2) abaixo. Pedi para que os alunos formassem duplas e partir dali desenhassem o mapa mundi identificando um bloco econômico e não esquecendo de colocar a legenda. A atividade foi muito proveitosa, pois pude perceber que os alunos estavam bem envolvidos na atividade e também foi importante porque pôde ser observado

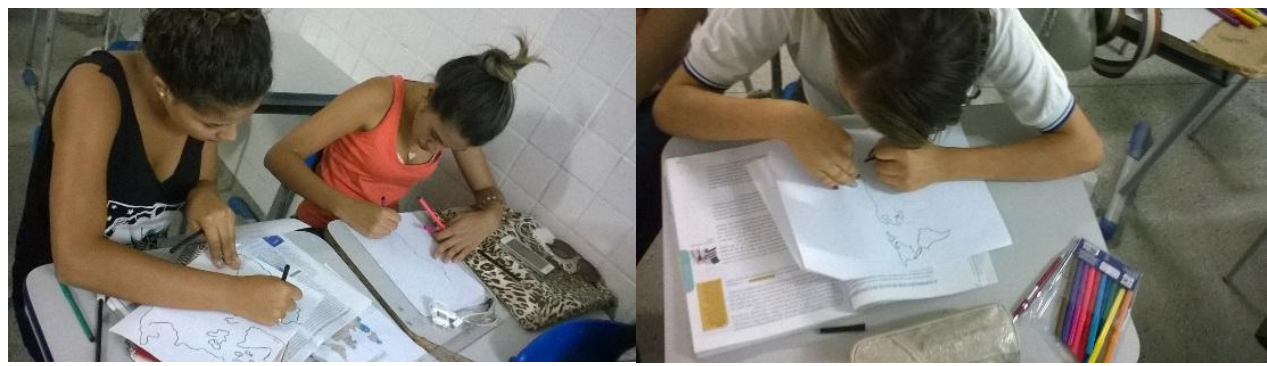
como estavam os conhecimentos desses alunos com relação ao conteúdo.

Figura 2: Oficina de atividade lúdica com mapas - Fonte: GOMES 2015

Foi realizada uma aula de campo para o Museu de Minérios RN do Instituto Federal de Ciência, Educação e Tecnologia do Rio Grande do Norte para que os alunos pudessem unir a teoria à prática ministrada em sala de aula. Foi uma viagem muito esperada, pois segundo a professora colaboradora é muito raro os alunos da Escola Professora Josefa Sampaio terem aulas de campo devido à falta de transporte. Tenho certeza que foi uma aula bastante proveitosa para todos que ali estiveram. 


\section{Conclusões}

O Estágio Supervisionado é uma atividade indispensável na construção da identidade profissional uma vez que o professor, enquanto sujeito da própria formação, constrói seus saberes ancorados na superação da fragmentação do conhecimento, favorecendo a visão e o trabalho compartilhado no contexto educacional.

Além disso, com a prática do Estágio Supervisionado de Licenciatura o aluno (estagiário) aprende a resolver problemas e achar soluções e passa a entender a grande importância que tem o educador na formação pessoal e profissional de seus alunos.

Durante o Estágio Supervisionado em Geografia foi possível observar que existem escolas que realmente acreditam no ensino de qualidade e nas potencialidades de seus alunos, que buscam sempre incentivá-los a buscar o conhecimento e integrá-lo às suas experiências de vida, e que estão sempre procurando atender às necessidades e as curiosidades deles.

Podemos concluir com isto, que o estágio supervisionado funciona como uma forma de inclusão dos estudantes universitários à realidade e vivência de uma escola. Visto que esse contato é de fundamental importância para a formação do novo professor que está sendo formado.

\section{Referências}

EDUCAÇÃO, Assecom. Escola Estadual Josefa Sampaio é reformada e ampliada após 18 anos de espera. 2013. Disponível em: <http://www.rneducacao.com/2013/03/escola-estadual-josefasampaio-e.html>. Acesso em: 26 out. 2015.

LIMA, Adriene Viana. Educação do campo e Pedagogia da Alternância: algumas considerações metodológicas. In: Entrelaçando: Revista Eletrônica de Culturas e Educação. N. 6, v.2, p. 46-60. $\begin{array}{llll}\text { Ano III } & \text { (2012). } & \text { Set.-dez. } & \text { 2012. }\end{array}$ em:<http://www.ufrb.edu.br/revistaentrelacando/downloads/edicao-no-07-ano-iii/200-4-educao-docampo-e-pedagogia-da-alternncia-adriene/download>. Acesso em: 26 out. 2015.

PIMENTA, Simone Garrido. Estagio é docência - $4^{\text {a }}$ Ed. São Paulo: Cortez, 2004. - (Coleção docência em formação). Série Saberes Pedagógicos. pag.46-74. 